\title{
Rhinoplasty Complications and Reoperations: Systematic Review
}

\author{
Paulo Fernando Tormin Borges Crosara ${ }^{1}$ Flávio Barbosa Nunes ${ }^{1}$ Danilo Santana Rodrigues ${ }^{1}$ \\ Ana Rosa Pimentel Figueiredo ${ }^{1}$ Helena Maria Gonçalves Becker ${ }^{1}$ Celso Goncalves Becker ${ }^{2}$ \\ Roberto Eustáquio Santos Guimarães ${ }^{1}$
}

${ }^{1}$ Ophthalmology and Otorhinolaryngology, Universidade Federal de Minas Gerais, Belo Horizonte, Brazil

2 Department of Ear Nose and Throat, Universidade Federal de Minas Gerais, Belo Horizonte, Minas Gerais, Brazil

Int Arch Otorhinolaryngol 2017;21:97-101.

\author{
Address for correspondence Paulo Fernando Tormin Borges Crosara, \\ Professor, Oftalmologia e Otorrinolaringologia, Universidade Federal \\ de Minas Gerais, Av Brasil numero 1438 / sala 1004, Belo Horizonte, \\ MG, 30140003, Brazil \\ (e-mail: paulocrosara@ufmg.br; pcrosara@hotmail.com).
}

\begin{abstract}
Keywords

- postoperative complications

- surgical revision

- rhinoplasty

Introduction This article is related to complications of rhinoplasty and its main causes of reoperations.

Objectives The objective of this study is to perform a systematic review of literature on complications in rhinoplasty.

Data Synthesis The authors conducted a survey of articles related to key terms in the literature by using three important databases within 11 years, between January 2002 and January 2013. We found 1,271 abstracts and selected 49 articles to this review. Conclusion The main results showed that the number of primary open rhinoplasty was 7902 (89\%) and 765 closed (11\%) and the percentage of reoperations in primary open complete rhinoplasties was $2.73 \%$ and closed complete was $1.56 \%$. The statistical analysis revealed a value of $p=0.071$. The standardization of terms can improve the quality of scientific publications about rhinoplasty. There is no difference between primary open or closed rhinoplasty techniques in relation to reoperations.
\end{abstract}

\section{Introduction}

Rhinoplasty is one of the most complex surgical procedures in plastic surgery. The nose, with its three-dimensional anatomical traits and complex function, interfere with emotional, respiratory, bio-behavioral and immunological factors. Rhinoplasty is a procedure widely sought after by patients because a change in center-facial aesthetics becomes very evident. All these factors influence the planned procedure and post-operative questions. So the detection of the major complications can help surgeons in surgical techniques and in guidelines to patients about the limits of procedures. Secondary rhinoplasty occurs for two main reasons: dissatisfaction with the expected result and incorrect technique or assessment of nasal anatomy. Compared with the primary rhino- plasty, surgical revision is even more difficult because its main objective is to modify the functional defects or cosmetics after complaints that a previous procedure was not successful according to the patients expectations. ${ }^{1}$

Our study is a case series analysis, where we have a certain technique, the description of patients, and their results. A recent way to evaluate results is the questionnaire on quality of life (QOL) and, more specifically, the Rhinoplasty Outcome Evaluation (ROE) or Rhinoplasty Outcomes Assessment. The latter consists of six questions, two for each factor considered critical to patient satisfaction (physical, emotional, and social). Quality of life can be defined as the individual's perception of their position in life in the context of culture and value systems in which they live, and in relation to objectives, expectations, standards, and concerns. ${ }^{2}$ received

February 16, 2016

accepted

June 18, 2016

published online

September 22, 2016
DOI http://dx.doi.org/

10.1055/s-0036-1586489. ISSN 1809-9777.
Copyright $\odot 2017$ by Thieme-Revinter

Publicações Ltda, Rio de Janeiro, Brazil
License terms

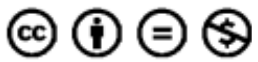


We conducted a systematic review based on a literature search of scientific articles indexed or not, with similar characteristics, but that alone has little value. Once grouped, the results can achieve a greater significance level. This method is among the most important tools in response to clinical and surgical issues. A systematic review (synonyms: systematic overview; overview; qualitative review) is designed to answer a specific question and uses explicit and systematic methods to identify, select, and critically evaluate studies, allowing researchers to collect and analyze the data from the studies included. Statistical methods (meta-analysis) may or may not be used in the analysis and synthesis of the results of the included studies. Thus, the systematic review relies on such comprehensive structuring to avoid bias in each of its parts. ${ }^{3}$

The objective is to define the reoperation rate, the main complications, and causes of secondary surgery in rhinoplasty based on the systematic literature review and possible development of a meta-analysis.

\section{Review of Literature}

We conducted searches in MEDLINE, COCHRANE, SCIELO, LILACS SCIRUS, and PUBMED CENTRAL databases. The terms used in the English language were "rhinoplasty and outcomes," "revisional rhinoplasty," "rhinoplasty complication," "secondary rhinoplasty." The research period was limited to 11 years between January 2002 and January 2013, as well as research in humans and in English (-Table 1). We assessed article summaries in English, Portuguese, Spanish, and French. Once selected, the researchers converted the full articles into Microsoft Word for analysis. The search generated over 98 references analyzed according to the criteria below.

Inclusion criteria: number of cases with primary and / or secondary rhinoplasty, in which we could detect: the number of cases, age, sex, duration, or follow-up, change that motivated procedure, technique used, complications, and re-operations.

Exclusion criteria: language used is not accessible to researchers, number of cases relating to tumors, complex post-traumatic reconstruction, use of allografts, rhinoplasty for cleft patients, children, the absence of: number of cases, age, duration or follow-up, which would have led to procedure, technique, complications, and re-operations.

Table 1 Results obtained following the search terms

\begin{tabular}{|l|l|}
\hline Terms used & Results \\
\hline rhinoplasty and outcomes & 647 \\
\hline rhinoplasty and roe ROE & 9 \\
\hline rhinoplasty and quality of life & 38 \\
\hline revisional rhinoplasty & 170 \\
\hline rhinoplasty complication & 105 \\
\hline secondary rhinoplasty & 204 \\
\hline reference of the articles selected & 98 \\
\hline Total & 1271 \\
\hline
\end{tabular}

Table 2 Terms used to group preoperative complaints

\begin{tabular}{|l|}
\hline Unaesthetic scar in columella \\
\hline Columella changes \\
\hline Tip changes \\
\hline Supratip changes \\
\hline Alar changes \\
\hline Nostril changes \\
\hline Middle valve changes \\
\hline Nasal bone changes \\
\hline
\end{tabular}

Once we selected the abstract, we read the article for data collection. We filed all selected articles in the Mendeley platform. The initial Excel table was filled by creating two large subdivisions; the first relating to the grounds and / or surgical findings and the second related to the procedures used, complications, and secondary surgeries. Then, we worked on each of these divisions and grouped data again according to -Tables $\mathbf{2}$ and $\mathbf{3}$. There were two large analyses, one referring to patients of primary rhinoplasty series and the second concerning series of secondary cases. We ran the information from the Excel table through a statistical analysis. ${ }^{1,4-50}$

Research has found 1271 articles evaluable. Of these we selected 151 articles that potentially met the inclusion criteria. After studying the articles, 49 were included in the survey.

As described in - Table 4, three articles (6.12\%) used ROE or $\mathrm{QOL}$, one (2\%) had grade of recommendation $3 \mathrm{~b}$, and $48(98 \%)$ had recommendation grade 4 .

The total rhinoplasty found in selected studies was 11035 , and 9655 (87.5\%) primary and 1380 (12.5\%) secondary.

In primary rhinoplasty taken together, we find as preoperative complaints: $61.0 \%$ nasal tip, $2.2 \%$ nasal valve, $8.0 \%$ nasal wing, $19.6 \%$ nasal dorsum and $9.0 \%$ nasal pyramid. -Figs. 1 and 2.

In complete primary rhinoplasty, the average age was 30.5 years. The females totaled $75.1 \%$ of cases and $24.9 \%$ of male cases. The average time postoperative follow-up was 25 months. The number of complete primary open rhinoplasty was $7902(89 \%)$ and was closed $765(11 \%)$. The percentage

Table 3 Terms used to group accomplished procedures

\begin{tabular}{|l|}
\hline Tip definition \\
\hline Grafts in nasal tip \\
\hline Grafts in nasal wing \\
\hline Alectomy \\
\hline Grafts stake \\
\hline Graft expanders middle nasal valve \\
\hline Procedures in nasal columella \\
\hline Grafts in the nasal dorsum \\
\hline Osteotomies \\
\hline Nasal dorsum reduction \\
\hline
\end{tabular}


Table 4 Articles with use of ROE or QOL, Degree of Recommendation and Level of Evidence

\begin{tabular}{|l|l|}
\hline Total articles & $49(100 \%)$ \\
\hline ROE or QOL & $3(6.12 \%)$ \\
\hline Degree of Recommendation 4 & $48(98 \%)$ \\
\hline Degree of Recommendation 3 & $1(2 \%)$ \\
\hline Level of Evidence 4 & $48(98 \%)$ \\
\hline Level of Evidence 3B & $1(2 \%)$ \\
\hline
\end{tabular}

of reoperations in complete primary rhinoplasty by open surgery was $2.73 \%$ and the complete closed was $1.56 \%$, and the statistical analysis showed a value of $p=0.071$.

Individually analyzing the closed surgery, only to access the bone pyramid and middle third (untreated nasal tip) we found 814 cases with reoperation rate of $1.47 \%$.

Regarding alectomias have been reported 174 cases with 4.79\% complication rate.
In the group of surgeries classified as secondary, we detected 1380 cases of which 593 (43.0\%) were operated by closed access and $279(20.2 \%)$ as open; it is not possible to compare the two groups. The reoperation rate in this group as a whole was $1.73 \%$. Changes that motivated the surgery were: $22.5 \%$ nasal tip, $16.4 \%$ nasal valve, $8.9 \%$ nasal wings, $27.9 \%$ nasal dorsum, 20.1\% nasal pyramid and 3.9\% columela nasal. - Figs. 1 and 2.

\section{Discussion}

When we study the selected articles we see almost all simple case series reports. Describe certain technique or type of anatomical alteration. The use of ROE or QOL was very limited and the degree of recommendation and level of significance was also not very significant, as seen in - Table 4 . These works do not reduce the degree of impact of a systematic literature review because the set of similar cases is which will result in a reliable and significant study. When we see such a large number of works without the use of ROE or QOL, with low

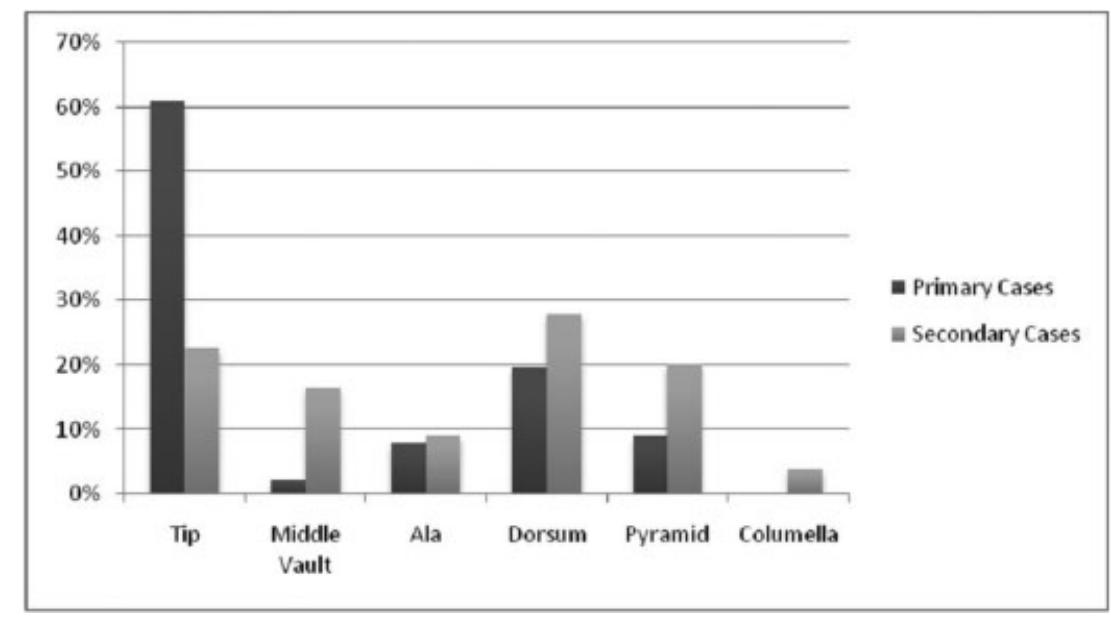

Fig. 1 Percentage alterations found in primary and secondary rhinoplasty.

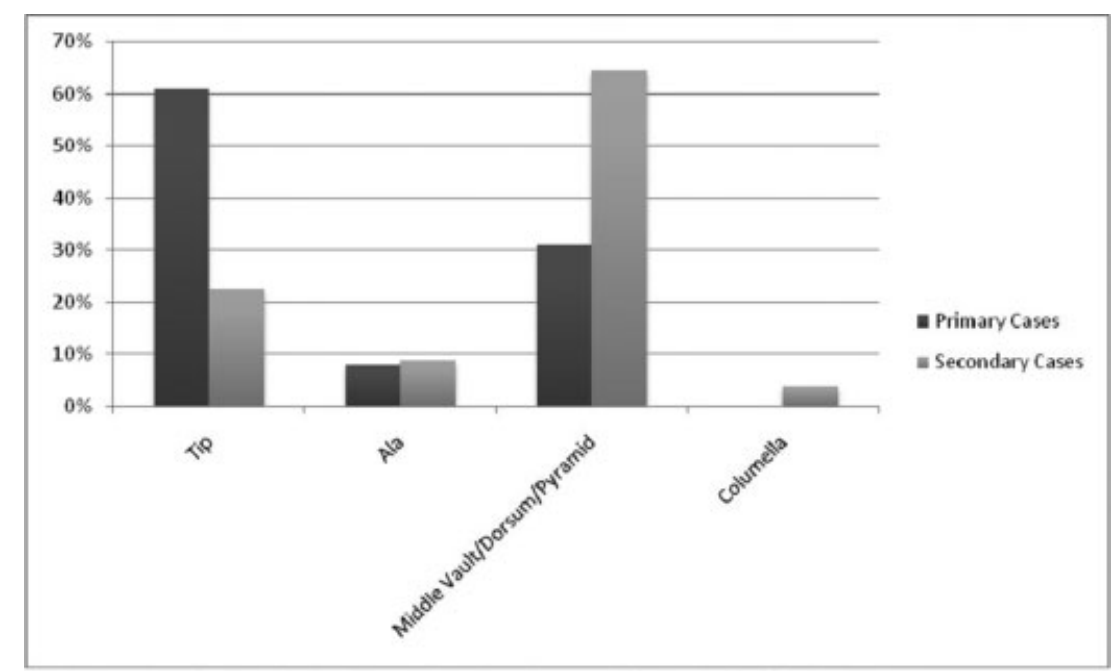

Fig. 2 Percentage alterations found in primary and secondary rhinoplasty with grouping of the alterations in valve, dorsum and pyramid in relation to nasal tip. 
impact and improper methodology requires us think about how these studies have been done compared with the other ENT subspecialties. Another important finding was the large amount of terms and techniques that are used in nasal anatomy. This brings problems in the grouping of data and treatment options. Obviously, a first step toward comparable articles to each other would be the standardization of the nomenclature and usage techniques. If we have low-impact articles, we also have a wide field of study, in which Works with good design and systematic will guide effective treatment methods with scientific value. ${ }^{2}$

To compare the data found there was need for grouping of key terms found in the preoperative period, the technique used and postoperative findings. This option does not compromise the findings, once it we do not determine if a technique is superior to another. The findings may in the future mark out other work. A systematic review of literature can also demonstrate the impossibility of obtaining comparable and reliable results. ${ }^{3}$

For reviewing the articles we determine a large number of rhinoplasty, 11035 cases and 9655 (87.5\%) primary and in $1380(12.5 \%)$ secondary, mostly in women. Regarding the preoperative alterations, there was a reversal of the prevalence, and the nasal tip (61.0\%) more found in primary surgeries and valve-dorsum-pyramid set (64.4\%) in the secondary. This can be explained since the primary rhinoplasty series seek to describe any technique or specific changes. Already in secondary rhinoplasty series we see that nasal tip changes do not lead to the majority of reviews, but the changes valvedorsum-pyramid. This may be a reflection of the inexperience of first surgeon or low reporting on items that specifically describe nasal tip changes.

The comparison between the process of open and closed access in complete primary rhinoplasty in relation to the percentage of reoperations showed a statistical analysis with $p=0.071$. So there is not statistical significance in the choice of open or closed access. This shows that there is not better access, leaving the surgeon responsible for the choice of which technique to use, taking into consideration the indication for the procedure, the experience of the professional and the limitation of the surgical technique, among other factors.

The closed technique to access the nasal bone pyramid in the middle third, without nasal tip manipulation has low complication (1.47\%), similar to closed rhinoplasty.

The alectomy was the procedure with the highest complication rate $(4.79 \%)$, alerting us of its importance, since its correction is difficult to treat.

In secondary surgery (1380 cases), only $60.3 \%$ specified the prior access ( $43.0 \%$ closed and $20.2 \%$ open), making it difficult to compare these groups. The recovery rate of these patients (patients who underwent a tertiary surgery) is low (1.73\%). However, this does not reflect patient satisfaction, due to the lack of questionnaires such as the ROE and QOL. The American literature had the greatest number of publications available. In the United States, the open technique is present in most surgeries. As for South America, the endonasal technique is preferred. 1

\section{Final Comments}

The scientific literature that addresses the theme rhinoplasty is increasing. There is still a limitation of articles with a good level of evidence and the standardization of terms could facilitate and increase production within this literary theme. The use of standardized questionnaires, such as the ROE and the QOL, with the choice of appropriate design and systematic production can enrich the literature on this topic and make the evaluation more objective as a result.

The choice of surgical approach does not interfere in the reoperation rate in primary cases.

We have a high reoperation rate in alectomies.

The secondary surgeries occur mostly by change valvedorsum-pyramid.

\section{References}

1 Thomson C, Mendelsohn M. Reducing the incidence of revision rhinoplasty. J Otolaryngol 2007;36(2):130-134 10.2310/7070.2007.0012

2 Izu SC, Kosugi EM, Brandão KV, et al. Normal values for the Rhinoplasty Outcome Evaluation (ROE) questionnaire. Braz J Otorhinolaryngol 2012;78:76-79 http://www.ncbi.nlm.nih.gov/ pubmed/22936141

3 Akobeng AK. Principles of evidence based medicine. Arch Dis Child 2005;90(8):837-840 10.1136/adc.2005.071761

4 Acarturk S, Arslan E, Demirkan F, Unal S. An algorithm for deciding alternative grafting materials used in secondary rhinoplasty. J Plast Reconstr Aesthet Surg 2006;59(4):409-416, discussion 417-418 10.1016/j.bjps.2005.05.023

5 Akcam T, Friedman O, Cook TA. The effect on snoring of structural nasal valve dilatation with a butterfly graft. Arch Otolaryngol Head Neck Surg 2004;130(11):1313-1318 10.1001/archotol.130.11.1313

6 Arslan E, Majka C, Beden V. Combined use of triple cartilage grafts in secondary rhinoplasty. J Plast Reconstr Aesthet Surg 2007; 60(2):171-179 10.1016/j.bjps.2006.04.014

7 Arslan E, Unal S, Demirkan F, Gurbuz O, Beden V. Augmentation rhinoplasty with a combination of triple cartilage grafts for secondary rhinoplasty in a middle-aged population. Aesthetic Plast Surg 2005;29(4):240-245 10.1007/s00266-004-0079-4

8 Avşar Y. Nasal hump reduction with powered micro saw osteotomy. Aesthet Surg J 2009;29(1):6-11 10.1016/j.asj.2008.10.009

9 Boccieri A. Mini spreader grafts: a new technique associated with reshaping of the nasal tip. Plast Reconstr Surg 2005;116(5): 1525-1534 10.1097/01.prs.0000182787.99210.10

10 Boccieri A, Marianetti TM. Perichondrium graft: harvesting and indications in nasal surgery. J Craniofac Surg 2010;21(1):40-44 10.1097/SCS.0b013e3181c362df

11 Bracaglia R, Fortunato R, Gentileschi S. Double lateral osteotomy in aesthetic rhinoplasty. Br J Plast Surg 2004;57(2):156-159 10.1016/j.bjps.2003.11.008

12 Bracaglia R, Fortunato R, Gentileschi S. Secondary rhinoplasty. Aesthetic Plast Surg 2005;29(4):230-239 10.1007/s00266-0050034-z

13 Camirand A, Doucet J, Harris J. Nose surgery: how to prevent a middle vault collapse-a review of 50 patients 3 to 21 years after surgery. Plast Reconstr Surg 2004;114(2):527-534 10.1097/01. PRS.0000128425.01547.45

14 Chang CWD, Simons RL. Hockey-stick vertical dome division technique for overprojected and broad nasal tips. Arch Facial Plast Surg 2008;10(2):88-92 10.1001/archfaci.10.2.88

15 Cingi C, Eskiizmir G, Cakli H. Comparative analysis of primary and secondary rhinoplasties according to surgeon's perspective, 
patient satisfaction, and quality of life. Ann Otol Rhinol Laryngol 2012;121(5):322-327

16 Clark JM, Cook TA. The 'butterfly' graft in functional secondary rhinoplasty. Laryngoscope 2002;112(11):1917-1925 10.1097/ 00005537-200211000-00002

17 Constantian MB. Differing characteristics in 100 consecutive secondary rhinoplasty patients following closed versus open surgical approaches. Plast Reconstr Surg 2002;109(6): 2097-2111 10.1097/00006534-200205000-00048

18 Daniel RK. Rhinoplasty: septal saddle nose deformity and composite reconstruction. Plast Reconstr Surg 2007;119(3): 1029-1043 10.1097/01.prs.0000252503.30804.5e

19 Daniel RK. Middle Eastern rhinoplasty in the United States: Part I. Primary rhinoplasty. Plast Reconstr Surg 2009;124(5):1630-1639 10.1097/PRS.0b013e3181babc95

20 Davis AM, Simons RL, Rhee JS. Evaluation of the Goldman tip procedure in modern-day rhinoplasty. Arch Facial Plast Surg 2004; 6(5):301-307 10.1001/archfaci.6.5.301

21 de la Peña-Salcedo JA, Soto-Miranda MA, Lopez-Salguero JF. Treatment protocol for "Mestizo nose" with open rhinoplasty. Aesthetic Plast Surg 2011;35(6):972-988 10.1007/s00266-0119717-9

22 Dosanjh AS, Hsu C, Gruber RP. The hemitransdomal suture for narrowing the nasal tip. Ann Plast Surg 2010;64(6):708-712 10.1097/SAP.0b013e3181b02701

23 Elahi MM, Jackson IT, Moreira-Gonzalez A, Yamini D. Nasal augmentation with Surgicel-wrapped diced cartilage: a review of 67 consecutive cases. Plast Reconstr Surg 2003;111(3):1309-1318, discussion 1319-1321 10.1097/01.PRS.0000047442.41691.C8

24 Foda HMT. External rhinoplasty for the Arabian nose: a columellar scar analysis. Aesthetic Plast Surg 2004;28(5):312-316 10.1007| s00266-003-3126-7

25 Foda HMT. Rhinoplasty for the multiply revised nose. Am J Otolaryngol 2005;26(1):28-34 10.1016/j.amjoto.2004.06.014

26 Funk E, Chauhan N, Adamson PA. Refining vertical lobule division in open septorhinoplasty. Arch Facial Plast Surg 2009;11(2): 120-125 10.1001/archfacial.2008.527

27 Gandomi B, Arzaghi MH, Rafatbakhsh M. The effectiveness of modified vertical dome division technique in reducing nasal tip projection in rhinoplasty. Iran J Med Sci 2011;36(3): 196-200 http://www.pubmedcentral.nih.gov/articlerender. fcgi artid $=3556763 \&$ tool $=$ pmcentrez\&rendertype $=$ abstract. Accessed April 82013

28 Gruber RP, Kryger G, Chang D. The intercartilaginous graft for actual and potential alar retraction. Plast Reconstr Surg 2008; 121(5):288e-296e 10.1097/PRS.0b013e31816c3b9a

29 Gryskiewicz JM. Waste not, want not: the use of AlloDerm in secondary rhinoplasty. Plast Reconstr Surg 2005;116(7): 1999-2004 10.1097/01.prs.0000191180.77028.7a

30 Gubisch W, Eichhorn-Sens J. Overresection of the lower lateral cartilages: a common conceptual mistake with functional and aesthetic consequences. Aesthetic Plast Surg 2009;33(1):6-13 10.1007/s00266-008-9267-y

31 Gubisch W, Eichhorn-Sens J. The sliding technique: a method to treat the overprojected nasal tip. Aesthetic Plast Surg 2008;32(5): 772-778 10.1007/s00266-008-9211-1

32 Gürlek A, Ersoz-Ozturk A, Celik M, Firat C, Aslan S, Aydogan H. Correction of the crooked nose using custom-made high-density porous polyethylene extended spreader grafts. Aesthetic Plast Surg 2006;30(2):141-149 10.1007/s00266-005-0152-7

33 Guyuron B, Varghai A. Lengthening the nose with a tongue-andgroove technique. Plast Reconstr Surg 2003;111(4):1533-1539, discussion 1540-1541 10.1097/01.PRS.0000049637.42449.80

34 Keskin M, Tosun Z, Savaci N. The importance of maintaining the structural integrity of the lateral crus in tip rhinoplasty. Aesthetic Plast Surg 2009;33(6):803-808 10.1007/s00266-009-9358-4

$35 \mathrm{Kim}$ JS, Han KH, Choi TH, et al. Correction of the nasal tip and columella in Koreans by a complete septal extension graft using an extensive harvesting technique. J Plast Reconstr Aesthet Surg 2007;60(2):163-170 10.1016/j.bjps.2006.03.055

36 Kridel RWH, Castellano RD. A simplified approach to alar base reduction: a review of 124 patients over 20 years. Arch Facial Plast Surg 2005;7(2):81-93 10.1001/archfaci.7.2.81

37 Margulis A, Harel M. Management of severe tip ptosis in closed rhinoplasty: the horizontal columellar strut. J Plast Reconstr Aesthet Surg 2007;60(4):400-406 10.1016/j.bjps.2006.10.013

38 Mayaleh HA. The onlay folded flap (OFF): a new technique for nasal tip surgery. Aesthetic Plast Surg 2011;35(1):73-79 10.1007/ s00266-010-9562-2

39 Pensler JM. The role of the upper lateral cartilages in aesthetic rhinoplasty. Aesthet Surg J 2009;29(4):290-294 10.1016/j. asj.2009.04.006

40 Pensler JM. The septal strut for nasal projection following closed rhinoplasty. Aesthet Surg J 2006;26(3):275-279

41 Ponsky D, Eshraghi Y, Guyuron B. The frequency of surgical maneuvers during open rhinoplasty. Plast Reconstr Surg 2010; 126(1):240-244 10.1097/PRS.0b013e3181dc54da

42 Rohrich RJ, Hoxworth RE, Kurkjian TJ. The role of the columellar strut in rhinoplasty: indications and rationale. Plast Reconstr Surg 2012;129(1):118e-125e 10.1097/PRS.0b013e3182362b7a

43 Rohrich RJ, Raniere J Jr, Ha RY. The alar contour graft: correction and prevention of alar rim deformities in rhinoplasty. Plast Reconstr Surg 2002;109(7):2495-2505, discussion 2506-2508

44 Saltman BE, Pearlman SJ. Incidence of alarplasty in primary and revision rhinoplasty in a private practice setting. Arch Facial Plast Surg 2009;11(2):114-118 10.1001/archfacial.2008.521

45 Seneldir S, Korkut AY, Coskun BU, Teker AM, Gedikli O, Kahya V. Unilateral osteotomies for external bony deviation. J Craniofac Surg 2010;21(6):1890-1893 10.1097/SCS.0b013e3181f4af44

46 Skouras A, Asimakopoulou F-A, Skouras G, Divritsioti M, Dimitriadi K. Use of the Goldman technique to correct both the overprojected and the broad nasal tip. Aesthetic Plast Surg 2012;36(1): 54-61 10.1007/s00266-011-9780-2

47 Tellioğlu AT, Özakpinar HR, Cakir B, Tekdemir I. Importance of the levator labii alaeque nasi muscle in dorsal septal deviations. J Craniofac Surg 2011;22(2):446-449 10.1097/ SCS.0b013e3182077ae5

48 Timperley D, Stow N, Srubiski A, Harvey R, Marcells G. Functional outcomes of structured nasal tip refinement. Arch Facial Plast Surg 2010;12(5):298-304 10.1001/archfacial.2010.57

49 Oliveira PWB, Pezato R, Gregório LC. Deviated nose correction by using the spreader graft in the convex side. Braz JOtorhinolaryngol 2006;72:760-763

50 Yu K, Kim A, Pearlman SJ. Functional and aesthetic concerns of patients seeking revision rhinoplasty. Arch Facial Plast Surg 2010; 12(5):291-297 10.1001/archfacial.2010.62 